\title{
Unusual isolation of a hemiaminal product from 4-cyclohexyl-3-thiosemicarbazide and di-2-pyridyl ketone: Structural and spectral investigations
}

\author{
V. Suni ${ }^{\mathrm{a}}$, M.R. Prathapachandra Kurup ${ }^{\mathrm{a}, *}$, Munirathinam Nethaji ${ }^{\mathrm{b}}$ \\ ${ }^{a}$ Department of Applied Chemistry, Cochin University of Science and Technology, Kochi 682 022, Kerala, India \\ ${ }^{\mathrm{b}}$ Department of Inorganic and Physical Chemistry, Indian Institute of Science, Bangalore 560 012, India
}

\begin{abstract}
Stable hemiaminal product was isolated as single crystals from the condensation reaction of di-2-pyridyl ketone with 4-cyclohexyl-3thiosemicarbazide and structurally and spectrochemically characterized. The compound is the first report of a stable hemiaminal product of the condensation reaction of a substituted thiosemicarbazone. Spectral characterization was carried out using IR, UV-vis., ${ }^{1} \mathrm{H}$ NMR, ${ }^{13} \mathrm{C}$ NMR, COSY and HMQC. The compound crystallizes into a triclinic lattice with space group $P-1$. The molecule reveals a highly strained $Z E$ conformation and a one-dimensional packing is effected by a network of intermolecular hydrogen bonding interactions in the unit cell.
\end{abstract}

Keywords: Di-2-pyridyl ketone; Thiosemicarbazone; Hemiaminal; COSY; HMQC; Crystal structure

\section{Introduction}

The mechanistic pathway for the condensation of amines with carbonyl compounds involves the formation of a tetrahedral addition intermediate followed by its dehydration to yield imines [1]. These reaction intermediates, formerly referred to as 'carbinolamines', are thermodynamically unstable and are presently termed as 'hemiaminals' by IUPAC. The rate of formation of hemiaminals with the variation of substituents and $\mathrm{pH}$ has been the subject of several investigations and many conclusions were established with regard to their mechanisms. Isolation of the hemiaminal product was immaterial in the above studies and the products of the reactions of aldehydes with thiosemicarbazides were the corresponding thiosemicarbazones. However, here we report the isolation of the hemiaminal derivative, HL of a substituted thiosemicarbazone as crystalline product from a reaction between 4-cyclohexyl-3-thiosemicarbazide and di-2-pyridyl ketone

\footnotetext{
* Corresponding author. Tel.: +91484 2575804; fax: +914842577595 E-mail address: mrp@cusat.ac.in (M.R.P. Kurup).
}

(Scheme 1). The structure of the compound (Fig. 1) is established by single crystal X-ray diffraction and spectral studies.

Unsubstituted or alkyl substituted imines are highly reactive and imines are stabilized by one or more aryl groups attached to carbon or nitrogen. In such cases, the compounds are easily isolated and are called Schiff bases. Enhanced stability is imparted by aryl substituents due to the conjugative effect of the aryl group and the carbonnitrogen double bond. For Schiff bases such as hydrazones and semicarbazones, additional stability is imparted by a second nitrogen attached to the azomethine nitrogen [1]. In the light of these facts, a stable thiosemicarbazone is always expected as the final product of the condensation between a thiosemicarbazide and a carbonyl compound as observed from our previous findings [2-13]. From this standpoint also, the present study is interesting, since in spite of the stability factors such as aromatic substitution and hydrazinic nitrogen linkage, the imine product is not separated out here. This is contrary to the observations so far, since stable thiosemicarbazones are the commonly and easily obtained products after the condensation of a thiosemicarbazide with any carbonyl compound.

Previous reports of stable hemiaminal crystals were in the form of covalent intermediates during the reaction of an 


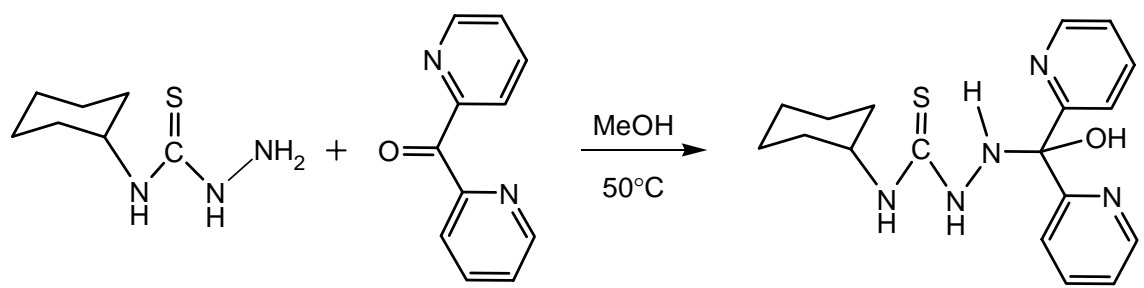

Scheme 1

aldehyde with lysine [14]. However, to the best of our knowledge, the title compound is the first report of the isolation of a hemiaminal product as single crystals from the condensation of a substituted thiosemicarbazide with any carbonyl compound.

\section{Experimental}

\subsection{Materials}

Cyclohexyl isothiocyanate (Fluka), hydrazine hydrate (Lancaster) and di-2-pyridyl ketone (Aldrich) were used as received. Infrared spectrum was recorded on ABB Bomem FTIR instrument as $\mathrm{KBr}$ pellets in the range $4000-500 \mathrm{~cm}^{-1}$. The ${ }^{1} \mathrm{H}$ NMR, ${ }^{13} \mathrm{C}$ NMR, COSY and HMQC spectra were recorded using Bruker DRX 500, with $\mathrm{CDCl}_{3}$ as solvent and TMS as the standard at Sophisticated Instruments Facility, Indian Institute of Science, Bangalore, India. The solid state reflectance spectrum was recorded on Ocean Optics, SD2000 Fibre Optic Spectrometer.

\subsection{X-ray data collection, structure solution and refinement}

The X-ray diffraction data were measured at room temperature $(293 \mathrm{~K})$ using a Bruker SMART APEX CCD diffractometer, equipped a fine focus sealed tube. Selected crystal data and data collection parameters are given in Table 1. The SMART software was used for data acquisition and the SAINT software for data extraction [15]. Empirical absorption corrections were made on the intensity data and the structure was refined by full-matrix least squares using the SHELXL system of programs [16] and the graphics tool was DIAMOND [17]. All non-hydrogen atoms were refined

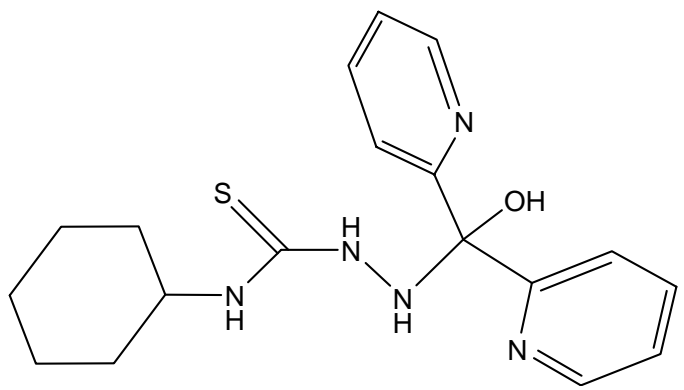

Fig. 1. Structure of compound HL. anisotropically. The hydrogen atoms were treated with a mixture of independent and constrained refinement and used for structure factor calculation only. The selected bond lengths and bond angles are listed in Table 2 .

\subsection{Synthesis of $H L$}

The hemiaminal, HL was prepared by adapting the following procedure. Ethanolic solutions of cyclohexyl isothiocyanate $(0.706 \mathrm{~g}, 5 \mathrm{mmol})$ and hydrazine hydrate $(0.250 \mathrm{~g}, 5 \mathrm{mmol})$ were mixed with constant stirring. The stirring was continued for one more hour and the white product, N(4)-cyclohexylthiosemicarbazide formed was washed, dried and recrystallised from ethanol. A methanolic solution of the $N(4)$-cyclohexyl thiosemicarbazide $(0.865 \mathrm{~g}$, $5 \mathrm{mmol}$ ) was then refluxed with di-2-pyridyl ketone $(0.921 \mathrm{~g}, 5 \mathrm{mmol})$ in $5 \mathrm{ml}$ methanol continuously for $4 \mathrm{~h}$ after adding 1-2 drops of acetic acid and the $\mathrm{pH}$ of

Table 1

Crystal data and structural refinement for HL

\begin{tabular}{ll}
\hline Parameters & $\mathrm{HL}$ \\
\hline Empirical formula & $\mathrm{C}_{18} \mathrm{H}_{25} \mathrm{~N}_{5} \mathrm{O}_{2} \mathrm{~S}$ \\
Formula weight, $M$ & 375.49 \\
Temperature, $T(\mathrm{~K})$ & $293(2)$ \\
Wavelength, Mo $\mathrm{K} \alpha(\AA)$ & 0.71073 \\
Crystal system & Triclinic \\
Space group & $P-1$ \\
Lattice constants $a(\AA), b(\AA), c$ & $8.571(5), 10.700(6), 11.104(6), 95$. \\
$(\AA), \alpha\left(^{\circ}\right), \beta\left(^{\circ}\right), \gamma\left({ }^{\circ}\right)$ & $089(9), 104.996(8), 91.481(9)$ \\
Volume $V\left(\AA^{3}\right)$ & $978.5(9)$ \\
$Z$ calculated density, $\rho\left(\mathrm{Mg} \mathrm{m}^{-3}\right)$ & $2,1.274$ \\
Absorption coefficient, $\mu\left(\mathrm{mm}^{-1}\right)$ & 0.188 \\
$F(000)$ & 400 \\
Crystal size (mm) & $0.35 \times 0.33 \times 0.30$ \\
$\theta$ Range for data collection & $1.91-26.25$ \\
Limiting indices & $-10 \leq h \leq 10,-13 \leq k \leq 13$, \\
& $-13 \leq l \leq 13$ \\
Reflections collected & 10253 \\
Unique reflections & $3978\left[R_{\text {int }}=0.0145\right]$ \\
Completeness to $\theta$ & $26.25(91.1 \%)$ \\
Absorption correction & Multi-scan \\
Max. and min. transmission & 0.9459 and 0.9373 \\
Refinement method & Full-matrix least-squares on $F^{2}$ \\
Data/restraints/parameters & $3978 / 0 / 335$ \\
Goodness-of-fit on $F^{2}$ & 1.029 \\
Final $R$ indices $[I>2 \sigma(I)]$ & $R_{1}=0.0443, w R_{2}=0.1165$ \\
$R$ indices (all data) & $R_{1}=0.0496, w R_{2}=0.1211$ \\
Largest difference peak and hole & 0.304 and -0.265 \\
(e $\left.\AA^{-3}\right)$ & \\
\hline
\end{tabular}


Table 2

Selected bond lengths $(\AA)$ and bond angles $\left({ }^{\circ}\right)$ of HL

\begin{tabular}{ll}
\hline & $\mathrm{HL}$ \\
\hline $\mathrm{O}(1)-\mathrm{C}(6)$ & $1.410(1)$ \\
$\mathrm{C}(6)-\mathrm{N}(3)$ & $1.464(2)$ \\
$\mathrm{N}(3)-\mathrm{N}(4)$ & $1.406(1)$ \\
$\mathrm{N}(4)-\mathrm{C}(12)$ & $1.340(2)$ \\
$\mathrm{C}(12)-\mathrm{S}(1)$ & $1.702(1)$ \\
$\mathrm{N}(3)-\mathrm{N}(4)$ & $1.371(4)$ \\
$\mathrm{C}(12)-\mathrm{N}(5)$ & $1.327(2)$ \\
$\mathrm{N}(5)-\mathrm{C}(13)$ & $1.461(2)$ \\
$\mathrm{C}(6)-\mathrm{C}(7)$ & $1.537(2)$ \\
$\mathrm{C}(5)-\mathrm{C}(6)$ & $1.527(2)$ \\
$\mathrm{O}(1)-\mathrm{C}(6)-\mathrm{N}(3)$ & $111.50(13)$ \\
$\mathrm{O}(1)-\mathrm{C}(6)-\mathrm{C}(7)$ & $110.03(13)$ \\
$\mathrm{C}(6)-\mathrm{N}(3)-\mathrm{N}(4)$ & $110.06(12)$ \\
$\mathrm{N}(3)-\mathrm{N}(4)-\mathrm{C}(12)$ & $120.68(13)$ \\
$\mathrm{N}(4)-\mathrm{C}(12)-\mathrm{S}(1)$ & $118.67(12)$ \\
$\mathrm{N}(4)-\mathrm{C}(12)-\mathrm{N}(5)$ & $117.22(15)$ \\
$\mathrm{S}(1)-\mathrm{C}(12)-\mathrm{N}(5)$ & $124.10(13)$ \\
$\mathrm{C}(12)-\mathrm{N}(5)-\mathrm{C}(13)$ & $125.38(16)$ \\
\hline
\end{tabular}

the solution was measured to be 4.7. On cooling the solution pale yellow crystals separated, which were filtered and washed with methanol. The crystals were recrystallized from ethanol and dried over $\mathrm{P}_{4} \mathrm{O}_{10}$ in vacuo. Single crystals suitable for $\mathrm{X}$-ray diffraction were obtained by slow evaporation of a methanolic solution of HL. Mp $124{ }^{\circ} \mathrm{C}$.

\section{Results and discussion}

The carbonyl addition of both weakly and moderately basic amines at weakly acidic $\mathrm{pH}$ values corresponds to a stepwise mechanism involving the formation of an unstable zwitterionic form of hemiaminal, which undergoes an intramolecular 'proton switch' or a proton transfer from a molecule of acid in order to convert into the hemiaminal product [18]. Usually, dehydration of the hemiaminal readily occurs as the next step yielding imines. One mechanistic approach towards the hemiaminal formation can be made by a possible hydrolysis of the imine. The hemiaminal is then obtained as the intermediate product, which finally yields the corresponding amine and carbonyl compounds. However, this mechanistic prediction seems to be unreliable in the present case, since once the imine, i.e., the di-2-pyridyl ketone 4-cyclohexyl-3-thiosemicarbazone is formed, it is expected to be stabilized by substituent effects and electron delocalization, which contradicts the possibility for getting hydrolysed. Hence, here the stabilization of the hemiaminal derivative can be rationalized only by taking into account the different electron transfer processes in the transition state during the condensation reaction. A suggestive mechanistic approach would be that the double bond formation and the rehybridisation of carbon and nitrogen atoms from tetrahedral $\mathrm{sp}^{3}$ structure of the hemiaminal to planar $\mathrm{sp}^{2}$ structure of the imine product lag behind other processes such as proton removal and electron delocalization in the transition state. As stated by Sayer and Jencks [19], the energetic advantage of maintaining significant overlap and bonding with the departing oxygen and hydrogen atoms in an $\mathrm{sp}^{3}$ hybridised transition state is more than enough to offset the stabilization achieved through a carbon-nitrogen double bond by rehybridisation towards a planar $\mathrm{sp}^{2}$ structure.

\subsection{Crystal structure of $H L$}

The compound crystallizes into a triclinic lattice with space group $P-1$ and the molecular structure of HL along with atom numbering scheme is given in Fig. 2. The molecule is non-planar as a whole and exists in the $Z E$ conformation since $Z$ and $E$ configurations are perceived about C6-N3 and C12-N4 bonds respectively. The central moiety comprising of atoms N3, N4, C12, S1 and N5 is almost planar with a maximum deviation of 0.0211 (3) $\AA$ from the mean plane. A torsion angle value of $177.86(11)^{\circ}$ corresponding to the S1-C12-N4-N3 moiety confirms the trans configuration of the thiocarbonyl S1 atom [27]. Unlike the azomethine double bond in thiosemicarbazones, the C6$\mathrm{N} 3$ bond distance $(1.464(2) \AA)$ is more close to that of a $\mathrm{C}-\mathrm{N}$ single bond [28], supporting the hemiaminal structure of the compound. In order to minimize the steric stain, the bulky pyridyl groups are deviated farthest with a dihedral angle of $75.31(1)^{\circ}$ between each other. The intramolecular hydrogen bonding interactions, viz., $\mathrm{N}(5)-\mathrm{H}(401) \cdots \mathrm{N}(3)$ and $\mathrm{O}(1)-\mathrm{H}(101) \cdots \mathrm{N}(2)$ lead to the formation of two five membered rings comprising of atoms $\mathrm{N}(3), \mathrm{N}(4), \mathrm{C}(12)$, $\mathrm{N}(5), \mathrm{H}(401)$ and $\mathrm{N}(2), \mathrm{C}(7), \mathrm{C}(6), \mathrm{O}(1)$ and $\mathrm{H}(101)$, respectively. Ring puckering analysis and least square planes calculations show that the cyclohexyl ring, $\mathrm{Cg}(3)$ adopts a chair conformation $\left(Q_{T}=0.5404 \AA\right)$.

The molecular packing of compound HL is shown in Fig. 3. The unit cell is viewed down the ' $a$ ' axis and the repeating unit consists of two molecules set in an offset fashion, arranged one-dimensionally in the crystal lattice. A residual water molecule in the crystal lattice is involved in extensive hydrogen bonding interactions with three of its

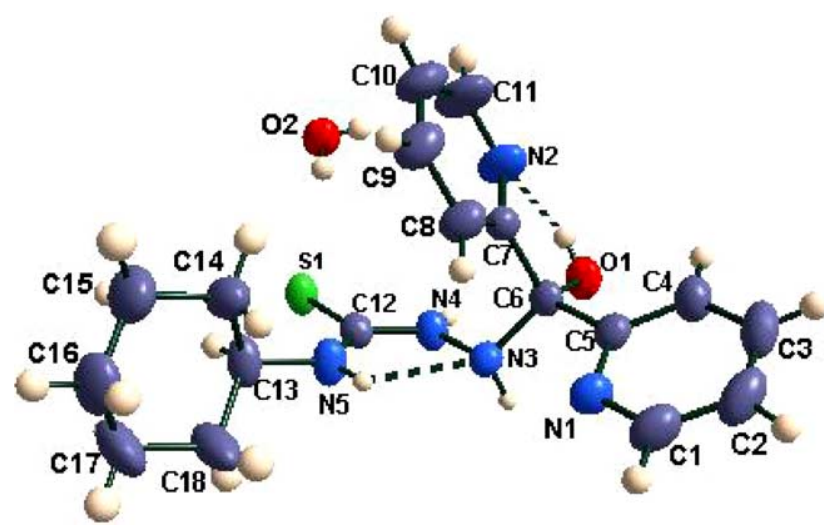

Fig. 2. Molecular structure of HL. Intramolecular hydrogen bonding interactions are shown as dashed lines. 


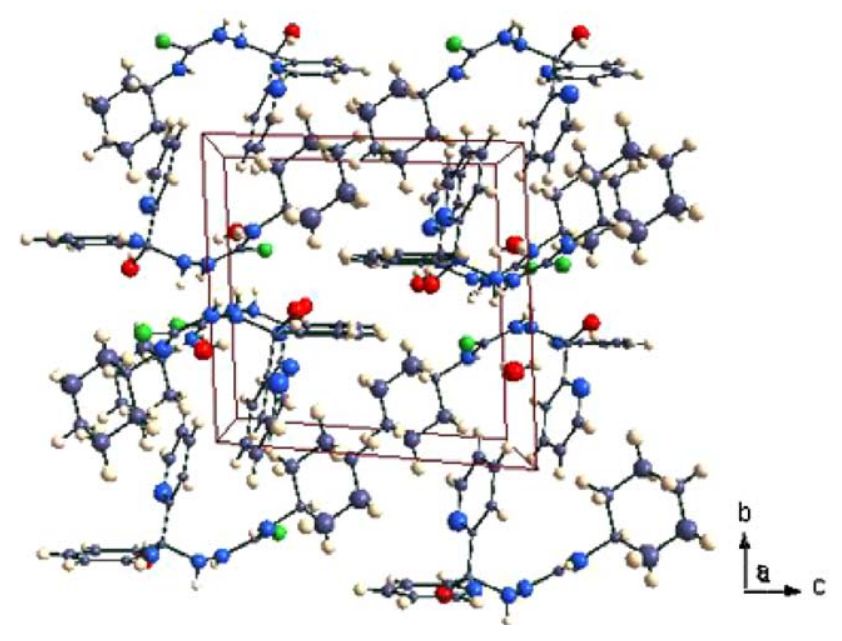

Fig. 3. Molecular packing diagram of HL, the unit cell is viewed down the ' $a$ ' axis.

adjacent molecules. Each thiocarbonyl sulphur atom is involved in two intermolecular hydrogen bonding interactions, $\mathrm{N}(4)-\mathrm{H}(301) \cdots \mathrm{S}(1)^{\mathrm{i}}\left[d_{D \cdots A}=3.410(1) \AA\right.$; $\mathrm{i}=-x+1,-y+1,-z+2]$ and $\mathrm{O}(2)-\mathrm{H}(202) \cdots \mathrm{S}(1)^{\mathrm{ii}}$ $\left[d_{D \cdots A}=3.490(1) \AA ; \mathrm{ii}=+x,+y,+z\right]$. The water molecule residue reveals two more intermolecular hydrogen bonds, viz., $\mathrm{N}(5)-\mathrm{H}(401) \cdots \mathrm{O}(2)^{\mathrm{iii}}\left[d_{D \cdots A}=3.035(2) \AA\right.$; $\mathrm{iii}=+x$, $+y,+z]$ and $\mathrm{O}(2)-\mathrm{H}(201) \cdots \mathrm{N}(1)^{\mathrm{iv}}\left[d_{D \cdots A}=2.823(2) \AA\right.$; iv $=x-1,+y,+z]$. These intermolecular hydrogen bonding interactions are mainly operational in the packing of the molecules in the crystal lattice, since $\pi-\pi$ and $\mathrm{C}-\mathrm{H} \cdots \pi$ interactions are weak, perceived at rather longer distances.

\subsection{Spectral studies}

The compound reveals well-defined molecular vibrations in the IR region. The $-\mathrm{OH}$ stretching vibration of the hydroxyl group at C6 is observed as a distinct peak at $3516 \mathrm{~cm}^{-1}$ in the IR spectrum. The intramolecular hydrogen bonding interactions of $\mathrm{C} 6-\mathrm{OH}$ with $\mathrm{N} 2$ observed in the crystal structure is confirmed by an additional broad, shallow $-\mathrm{OH}$ stretching peak observed at $3050 \mathrm{~cm}^{-1}$ [20]. The -NH symmetrical and asymmetrical stretching vibrations are perceived as two distinct peaks at 3726 and $3187 \mathrm{~cm}^{-1}$, respectively, while the $-\mathrm{CH}$ stretching vibrations of the cyclohexyl moiety are observed as sharp peaks at 2930 and $2853 \mathrm{~cm}^{-1}$. The absence of $\nu(\mathrm{SH})$ band around $2600 \mathrm{~cm}^{-1}$ suggest the existence of the thiosemicarbazone in the thione form and the $\mathrm{C}=\mathrm{S}$ stretching vibration is observed as a sharp peak at $1237 \mathrm{~cm}^{-1}$. In the solid state electronic spectrum of the compound, the $\pi^{*} \leftarrow \pi$ transitions of the pyridyl ring and the thiosemicarbazone moiety are observed at 38,610 and $37,310 \mathrm{~cm}^{-1}$, respectively, while the $\pi^{*} \leftarrow \mathrm{n}$ transition of the pyridyl nitrogen is observed as a broad band at $28,330 \mathrm{~cm}^{-1}$.

Structural studies reveal a highly strained conformation for the hemiaminal under study. A wide network of

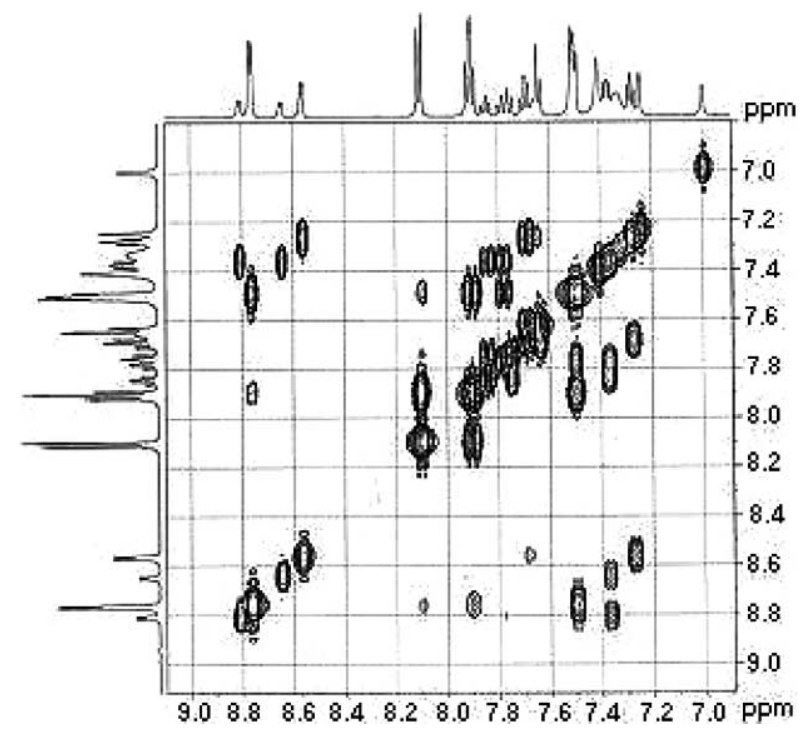

Fig. $4 .{ }^{1} \mathrm{H}-{ }^{1} \mathrm{H}$ COSY spectrum of $\mathrm{HL}$.

intra- and intermolecular hydrogen bonding interactions contribute towards the stability of packing in the crystal lattice. An interesting aspect of these interactions is that, unlike the previous reports of compounds of similar structures [21-25], in the present case, the similar protons of the two pyridyl rings are found to resonate at slightly varied frequencies. For instance, while the $\mathrm{C} 1-\mathrm{H}$ resonances are observed as double doublets at $8.60 \mathrm{ppm}$, an identical set of peaks are observed at $8.79 \mathrm{ppm}$, which can be assigned to C11-H protons. Assignment of these two double doublets to $\mathrm{C} 1-\mathrm{H}$ and $\mathrm{C} 11-\mathrm{H}$ protons is confirmed by the ${ }^{1} \mathrm{H}-{ }^{1} \mathrm{H}$ COSY spectrum of HL (Fig. 4). From the COSY, the C8-H proton $(8.10 \mathrm{ppm})$ is found to give off diagonal peaks at $8.79 \mathrm{ppm}$, resultant of its interaction with the proton on $\mathrm{C} 11$. Similarly, the off diagonal peaks around $8.60 \mathrm{ppm}$ correspond to the coupling interaction between $\mathrm{C} 1-\mathrm{H}$ and $\mathrm{C} 4-\mathrm{H}$ protons. The prominent intramolecular interaction $\mathrm{O} 1-\mathrm{H} 101-\mathrm{N} 2$ observed at a donor-acceptor distance of 2.577(1) $\AA$ from the crystal structure is instrumental in bringing about the different resonant frequencies. An increased charge density is experienced at $\mathrm{N} 2$ as a result of the hydrogen bonding, which shifts the $\mathrm{C} 11-\mathrm{H}$ resonance to more downfield compared to that of the $\mathrm{C} 1-\mathrm{H}$ proton. The molecule as a whole adapts a conformation in which the pyridyl ring with $\mathrm{N} 2$ is highly strained with active participation in the hydrogen bonding interactions. This results in a redistribution of electron density over the entire ring causing slight variations in the resonating frequencies of similar protons on the two pyridyl rings. Hence the $\mathrm{C} 2-\mathrm{H}$ and $\mathrm{C} 10-\mathrm{H}$ peaks are observed as triplets at 7.28 and $7.38 \mathrm{ppm}$ respectively, while the $\mathrm{C} 3-\mathrm{H}$ and $\mathrm{C} 9-\mathrm{H}$ resonances are perceived as multiplets centered around 7.71 and $7.50 \mathrm{ppm}$, respectively. Similarly, the doublets at $8.10 \mathrm{ppm}$ and the doublet of a triplet at $7.90 \mathrm{ppm}$ are assigned to $\mathrm{C} 8$ and $\mathrm{C} 4$ protons respectively. Assignment of these peaks to the respective 
protons is carried out with the help of ${ }^{1} \mathrm{H}-{ }^{1} \mathrm{H}$ correlation data available from the COSY spectrum.

Two sets of double doublets observed at 8.79 and $8.60 \mathrm{ppm}$ for protons $\alpha$ to pyridyl nitrogens attribute interesting features to the compound under study. The ${ }^{1} \mathrm{H}$ NMR spectrum of the present compound follows strictly first order with well-separated chemical shift positions for protons with different environments. For example, the signal for for $\mathrm{C} 1-\mathrm{H}$ proton appears as a double doublet around $8.60 \mathrm{ppm}$ due to the following coupling pattern observed between adjacent protons. At first, the proton at $\mathrm{C} 1$ couples with $\mathrm{C} 2$ proton, which splits the $\mathrm{C} 1-\mathrm{H}$ signal into a doublet. But $\mathrm{C} 1-\mathrm{H}$ also couples with $\mathrm{C} 3-\mathrm{H}$ so that each line of the $\mathrm{C} 1-\mathrm{H}$ is further split into two, giving a double doublet [20]. Although doublets and double doublets are reported previously [24,25], two well-defined sets of double doublets corresponding to two pyridyl protons in identical chemical environment are observed for the first time in a compound prepared form di-2-pyridyl ketone.

More distinctive features are associated with the resonance peaks of the protons on $\mathrm{N} 3$ and $\mathrm{N} 4$ atoms, which appear as a triplet at $7.84 \mathrm{ppm}$ corresponding to the two protons of identical chemical environments. Contrary to this, in all the previous observations of structurally related compounds, a sharp singlet at appreciable downfield values $(\delta 13-15 \mathrm{ppm})$ is observed for the $\mathrm{N} 3-\mathrm{H}$ proton [22]. Hence, in order to confirm the assignment of these triplets to $-\mathrm{NH}$ protons, the ${ }^{1} \mathrm{H}^{13}{ }^{13} \mathrm{C}$ correlation spectra were recorded. Absence of coupling of the triplets at $7.84 \mathrm{ppm}$ with the ${ }^{13} \mathrm{C}$ peaks in the HMQC experiments (Fig. 5) authenticated its assignment to $-\mathrm{NH}$ protons. The triplet is in accordance with the $2 I+1$ splitting $\left(I=1\right.$ for $\left.{ }^{14} \mathrm{~N}\right)$ of the resonance peak of the proton attached to the ${ }^{14} \mathrm{~N}$ nucleus. The appreciable electrical quadrupole moment at $\mathrm{N} 3$ and N4 nitrogens is able to induce an efficient spin relaxation to observe three

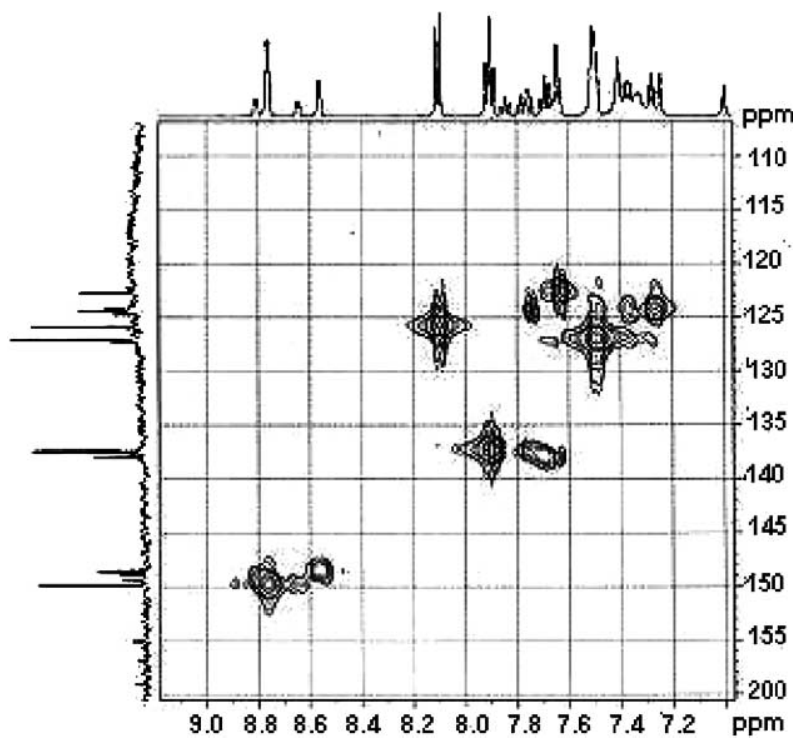

Fig. $5 .{ }^{1} \mathrm{H}-{ }^{13} \mathrm{C}$ HMQC spectrum of HL. well-defined spin states of the nitrogen nucleus, to which the proton responds by giving a triplet in the ${ }^{1} \mathrm{H}$ NMR spectrum.

The singlets at appreciable downfield in the previous reports were the result of rapid exchange and resultant decoupling of the $-\mathrm{NH}$ protons, which is found to be absent for the $\mathrm{N} 3$ and $\mathrm{N} 4$ protons in the present compound. However, the $\mathrm{N} 5 \mathrm{H}$ proton shows exchangeability at a low rate and turns up as a broad peak at $7.33 \mathrm{ppm}$. At low $-\mathrm{NH}$ exchange rates, ${ }^{14} \mathrm{~N}$ nucleus imparts moderate spin relaxation resulting in an intermediate lifetime for the spin states of nitrogen. Response of the $-\mathrm{NH}$ proton to these three spin states which are changing at a moderate rate is usually observed as a broad peak [26]. As the cyclohexyl moiety is observed in the chair conformation, the axial and equatorial hydrogens show slightly varied chemical shift values with the equatorial protons observed at more downfield (2.10-1.73 ppm) compared to their axial counterparts (1.42-1.22 ppm). However, the $\mathrm{C} 13-\mathrm{H}$ is deshielded by the adjacent electronegative nitrogen resulting in a multiplet at $4.21 \mathrm{ppm}$, which couples with the proton on N5. Assignment of the broad peak to N5 proton is also confirmed by the ${ }^{1} \mathrm{H}-{ }^{1} \mathrm{H}$ correlation experiments, since coupling of the $\mathrm{N} 5-\mathrm{H}$ proton with the $\mathrm{C} 13-\mathrm{H}$ proton of the cyclohexyl ring is clearly evident from the COSY.

\section{Supplementary data}

Crystallographic data for structural analysis has been deposited with the Cambridge Crystallographic Data Center, CCDC for compound HL. Copies of this information maybe obtained free of charge from The Director, CCDC 271996, 12 Union Road, Cambridge, CB2, IEZ, UK (fax: +44 1223336 033; e-mail: deposit@ccdc.cam.ac.uk or http://www.ccdc.cam.ac.uk).

\section{Acknowledgements}

The authors are thankful to Sophisticated Instruments Facility, IISc Bangalore, India for NMR measurements. DST IRPHA is kindly acknowledged for X-ray data collection. V. Suni is thankful to the State Council for Science, Technology and Environment, Kerala, India for financial support in the form of a fellowship.

\section{References}

[1] T.H. Lowry, K.S. Richardson, Mechanism and Theory in Organic Chemistry, third ed., Harper Collins, New York, 1987.

[2] A. Sreekanth, H.-K. Fun, M.R.P. Kurup, Inorg. Chem. Commun. 7 (2004) 1250.

[3] V. Philip, V. Suni, M.R.P. Kurup, Acta Crystallogr. C 60 (2004) 0856.

[4] M. Joseph, V. Suni, M.R.P. Kurup, M. Nethaji, A. Kishore, S.G. Bhat, Polyhedron 23 (2004) 3069. 
[5] R.P. John, A. Sreekanth, V. Rajakannan, T.A. Ajith, M.R.P. Kurup, Polyhedron 23 (2004) 2549.

[6] A. Sreekanth, S. Sivakumar, M.R.P. Kurup, J. Mol. Struct. 655 (2003) 47.

[7] A. Sreekanth, M.R.P. Kurup, Polyhedron 22 (2003) 3321.

[8] A. Usman, I.A. Razak, S. Chantrapromma, H.K. Fun, V. Philip, A. Sreekanth, M.R.P. Kurup, Acta Crystallogr. C58 (2002) 0652.

[9] P. Bindu, M.R.P. Kurup, T.R. Satyakeethy, Polyhedron 18 (1999) 321.

[10] C.K. Alphonsa, M.R.P. Kurup, Synth. React. Inorg. Met. 29 (1999) 805.

[11] B.S. Garg, M.R.P. Kurup, S.K. Jain, Y.K. Bhoon, Synth. React. Inorg. Met. 28 (1998) 1415.

[12] B.S. Garg, M.R.P. Kurup, S.K. Jain, Y.K. Bhoon, Trans. Met. Chem. 16 (1991) 111.

[13] B.S. Garg, M.R.P. Kurup, S.K. Jain, Y.K. Bhoon, Trans. Met. Chem. 13 (1988) 247.

[14] A. Heine, G. DeSantis, J.G. Luz, M. Mitchell, C.H. Wong, I.A. Wilson, Science 294 (2001) 369.

[15] Siemens, SMART and SAINT, Area Detector Control and Integration Software, Siemens Analytical X-ray Instruments Inc., Madison, WI, USA, 1996.

[16] G.M. Sheldrick, SHELXTL Version 5.1, Software Reference Manual, Bruker AXS Inc, Madison, WI, USA, 1997.
[17] K. Brandenburg, H. Putz, DIAMOND Version 3.0, Crystal Impact, GbR, Postfach 1251, D-53002 Bonn, Germany, 2004.

[18] J.M. Sayer, B. Pinsky, A. Schonbrunn, W. Washtien, J. Am. Chem. Soc. 96 (1974) 7998

[19] J.M. Sayer, W.P. Jencks, J. Am. Chem. Soc. 99 (1977) 464.

[20] W. Kemp, Organic Spectroscopy, third ed., Macmillan, Hampshire, 1996.

[21] J.K. Swearingen, D.X. West, Trans. Met. Chem. 26 (2001) 252.

[22] M. Joseph, V. Suni, C.R. Nayar, M.R.P. Kurup, H.-K. Fun, J. Mol. Struct. 705 (2004) 63.

[23] V. Philip, V. Suni, M.R.P. Kurup, M. Nethaji, Polyhedron 23 (2004) 1225.

[24] A. Sreekanth, M.R.P. Kurup, Polyhedron 23 (2004) 969.

[25] J.K. Swearingen, W. Kaminsky, D.X. West, Trans. Met. Chem. 27 (2002) 724

[26] R.M. Silverstein, G.C. Bassler, T.C. Morrill, Spectrometric Identification of Organic Compounds, fourth ed., Wiley, New York, 1981.

[27] D. Chattopadhyay, T. Banerjee, S.K. Mazumdar, S. Ghosh, R. Kuroda, Acta Crystallogr. C 43 (1987) 974.

[28] J.E. Huheey, E.A. Keiter, R.L. Keiter, Inorganic Chemistry, Principles of Structure and Reactivity, fourth ed., Harper Collins Colege Publishers, New York, 1993. 